\title{
La regulación religiosa en materia electoral mexicana: una explicación alternativa sobre sus diferencias
}

\author{
Alejandro Díaz Domínguez*
}

\begin{abstract}
The revision of the constitutional and legal norms in the electoral codes of the country allows us to conclude that there are different restriction levels for the various political parties and religious ministers, mainly due to historical reasons. The differences mentioned above show that the great majority of the regulations for political parties are divided in two groups, whereas those for ministers embrace several ranks. These differences are able to explain the various interpretations that electoral federal judges attain in similar cases.
\end{abstract}

Keywords: elections, church, clergyman, policy, religion, priest, tribunal.

\section{Resumen}

De la revisión de las normas constitucionales y legales en los códigos electorales del país se concluye que existen diferentes niveles de restricciones para partidos políticos y para ministros de culto, principalmente por razones históricas. Dichas diferencias muestran que la gran mayoría de las regulaciones para los partidos políticos se ubican en dos grandes grupos, mientras que las limitantes para los ministros abarcan todo tipo de graduaciones. Estas diferencias son las que pueden explicar las distintas interpretaciones que realizan los jueces electorales federales sobre asuntos similares.

Palabras clave: elecciones, iglesia, pastor, política, religión, sacerdote, tribunal.

* Secretario particular del magistrado presidente del Tribunal Electoral del Distrito Federal. Correo-e: alejandrodiaz@tedf.org.mx. 


\section{Introducción $^{1}$}

México preserva en su memoria histórica un momento crucial en el enfrentamiento directo entre religión y gobernantes: la guerra cristera, o “cristiada”, de 1926 a 1931 (Meyer, 2000, 2001 y 2002). Ya desde el constituyente de 1917, y más claramente desde finales de la década de los veinte, fue patente en la legislación mexicana la separación entre la política y la religión (Soberanes, 1998; Gill, 1999), sobre todo con las diferentes regulaciones callistas. $^{2}$

En la actualidad, las elecciones no son ajenas a ese debate, pues en los Artículos 3, 5, 24, 27 y 130 de la Constitución Política de los Estados Unidos Mexicanos (redactada en 1917), que fueron reformados hace casi tres lustros, ${ }^{3}$ se reformularon los criterios que hoy rigen las relaciones entre la Iglesia y el Estado como consecuencia del principio histórico de separación entre ambos. Allí se detallan diversas prohibiciones y limitantes en materia política y electoral, entre las que destaca la relativa a que los ministros de culto no podrán asociarse con fines políticos ni realizar proselitismo en favor o en contra de candidato, partido o asociación política alguna.

Como se muestra en el cuadro 1, la única reforma al Artículo 130 Constitucional, que detalla la relación entre religión y Estado, presenta ocho temas políticos: dos de ellos se mantuvieron intactos, uno presenta agregados y el resto sufrió modificaciones:

- Anteriormente, sólo los mexicanos por nacimiento podían ejercer el ministerio; ahora pueden ejercerlo los mexicanos por nacimiento, por naturalización y los extranjeros. ${ }^{4}$

- En el pasado se prohibía a los ministros "criticar" las leyes, a las autoridades y al gobierno, mientras que hoy se

\footnotetext{
${ }^{1}$ Agradezco los comentarios de dos dictaminadores anónimos, aunque la responsabilidad de lo aquí expresado es absolutamente mía.

2 Particularmente tres leyes: la penal del 2 de julio de 1926, la reglamentaria del Artículo 130 Constitucional del 18 de enero de 1927, y la relativa al número de sacerdotes que podrían ejercer el ministerio, del 30 de diciembre de 1931.

${ }^{3}$ Diario Oficial de la Federación del 28 de enero de 1992.

${ }^{4}$ Entre 1925 y 1936, 29 entidades establecieron límites numéricos para autorizar sacerdotes católicos y de cualquier otro culto tomando como base dos criterios: el poblacional y el total de cultos establecidos. El poblacional estableció el mínimo en un ministro por cada cuatro mil habitantes (Puebla en 1925) y el máximo de uno por cada 200 mil pobladores (Querétaro en 1934). El criterio del total de cultos establecidos determinó como mínimo un ministro por culto (Morelos en 1934, Chihuahua en 1936 y Colima en 1934) y el máximo de 38 por culto (Nuevo León en 1927). Véase Jiménez Urresti (1996) y, para matizar, Margadant (1991).
} 


\section{Cuadro 1 \\ Regulaciones en materia política. Reforma al Artículo 130 Constitucional}

\begin{tabular}{|c|c|c|}
\hline Temas & Artículo 130 (1917) & Articulo 130 (1992) \\
\hline Nacionalidad & $\begin{array}{l}\text { Para ejercer en México } \\
\text { el ministerio de cualquier } \\
\text { culto, se necesita ser } \\
\text { mexicano por nacimiento }\end{array}$ & $\begin{array}{l}\text { Los mexicanos podrán } \\
\text { ejercer el ministerio de } \\
\text { cualquier culto. Los } \\
\text { mexicanos, así como } \\
\text { los extranjeros, deberán, } \\
\text { para ello, satisfacer los } \\
\text { requisitos que señale la ley }\end{array}$ \\
\hline $\begin{array}{l}\text { Contenido de } \\
\text { comentarios }\end{array}$ & $\begin{array}{l}\text { Los ministros de los cultos } \\
\text { nunca podrán, en reunión } \\
\text { pública o privada } \\
\text { constituida en junta, ni en } \\
\text { actos del culto o de } \\
\text { propaganda religiosa, } \\
\text { hacer crítica de las } \\
\text { leyes fundamentales del } \\
\text { país, de las autoridades en } \\
\text { particular, o en general del } \\
\text { gobierno }\end{array}$ & $\begin{array}{l}\text { Tampoco podrán en reunión } \\
\text { pública, en actos de culto } \\
\text { o de propaganda religiosa, } \\
\text { oponerse a las leyes del } \\
\text { país o a sus instituciones, } \\
\text { ni agraviar, de cualquier } \\
\text { forma, los simbolos } \\
\text { patrios }\end{array}$ \\
\hline $\begin{array}{l}\text { Derecho a } \\
\text { ser votados }\end{array}$ & $\begin{array}{l}\text { Los ministros de los cultos } \\
\text { no tendrán voto activo }\end{array}$ & $\begin{array}{l}\text { En los términos de la ley } \\
\text { reglamentaria, los ministros } \\
\text { de cultos no podrán } \\
\text { desempeñar cargos públicos. } \\
\text { Quienes hubieren dejado } \\
\text { de ser ministros de cultos } \\
\text { con la anticipación y en la } \\
\text { forma que establezca la ley, } \\
\text { podrán ser votados }\end{array}$ \\
\hline Derecho a votar & ... ni pasivo & $\begin{array}{l}\text { Como ciudadanos tendrán } \\
\text { derecho a votar, pero no a } \\
\text { ser votados }\end{array}$ \\
\hline $\begin{array}{l}\text { Intervención } \\
\text { política }\end{array}$ & $\begin{array}{l}\text {... ni derecho para asociarse } \\
\text { con fines políticos }\end{array}$ & $\begin{array}{l}\text { Los ministros no podrán } \\
\text { asociarse con fines políticos } \\
\text { ni realizar proselitismo a } \\
\text { favor o en contra de candi- } \\
\text { dato, partido o asociación } \\
\text { politica alguna }\end{array}$ \\
\hline $\begin{array}{l}\text { Contenido de } \\
\text { publicaciones }\end{array}$ & $\begin{array}{l}\text { Las publicaciones } \\
\text { periódicas de carácter } \\
\text { confesional, } \\
\text { ya sea por su programa, } \\
\text { por su título o simplemente }\end{array}$ & $\begin{array}{l}\text { Tampoco podrán [...] en } \\
\text { publicaciones de carácter } \\
\text { religioso, oponerse a las } \\
\text { leyes del país o a sus } \\
\text { instituciones, ni agraviar, }\end{array}$ \\
\hline
\end{tabular}


continuación...

\begin{tabular}{|c|c|c|}
\hline Temas & Artículo 130 (1917) & Artículo 130 (1992) \\
\hline & $\begin{array}{l}\text { por sus tendencias } \\
\text { ordinarias, no podrán } \\
\text { comentar asuntos políticos } \\
\text { nacionales ni informar sobre } \\
\text { actos de las autoridades del } \\
\text { país, o de particulares, que } \\
\text { se relacionen directamente } \\
\text { con el funcionamiento de las } \\
\text { instituciones públicas }\end{array}$ & $\begin{array}{l}\text { de cualquier forma, los } \\
\text { símbolos patrios }\end{array}$ \\
\hline Alusiones & $\begin{array}{l}\text { Queda estrictamente } \\
\text { prohibida la formación de } \\
\text { toda clase de agrupaciones } \\
\text { políticas cuyo título tenga } \\
\text { alguna palabra o indicación } \\
\text { cualquiera que la relacione } \\
\text { con alguna confesión } \\
\text { religiosa }\end{array}$ & $\begin{array}{l}\text { Queda estrictamente } \\
\text { prohibida la formación de } \\
\text { toda clase de agrupaciones } \\
\text { políticas cuyo título tenga } \\
\text { alguna palabra o indicación } \\
\text { cualquiera que la relacione } \\
\text { con alguna confesión } \\
\text { religiosa }\end{array}$ \\
\hline Reuniones & $\begin{array}{l}\text { No podrán celebrarse en } \\
\text { los templos reuniones de } \\
\text { carácter político }\end{array}$ & $\begin{array}{l}\text { No podrán celebrarse en } \\
\text { los templos reuniones de } \\
\text { carácter político }\end{array}$ \\
\hline
\end{tabular}

Fuente: Diario Oficial de la Federación, 5 y 6 de febrero de 1917 (publicación y errata) y 28 de enero de 1992.

prohíbe "oponerse" a las instituciones y a los símbolos patrios. $^{5}$

- Se rechazaba el voto activo, que ahora se permite mediante la separación del ministerio con cierto número de años de anterioridad.

- Se otorgó derecho al voto pasivo. ${ }^{6}$

- Fue modificada la negativa para "comentar" e "informar" sobre asuntos políticos por "no oponerse" y "no agraviar" a las instituciones del país.

${ }^{5}$ Un ejemplo de "crítica" se presentó con el obispo de Huejutla y el delegado apostólico a causa del Artículo $3^{\circ}$ Constitucional y de las órdenes de aprehensión giradas en contra de ambos ministros por sus opiniones el 7 de noviembre de 1934 (Portes Gil, 1934).

${ }^{6}$ El Partido Comunista Mexicano fue el primero (1977) en proponer el reconocimiento del derecho al voto pasivo para los ministros de culto. Su propuesta fue vista con buenos ojos por simpatizantes de las teologías progresistas y otros sectores religiosos, tradicionalmente ajenos a las prácticas electorales y legislativas (Blancarte, 1992). Esa propuesta se presentó nuevamente en la bancada del Partido de la Revolución Democrática en 1992 cuando se discutían las reformas constitucionales al Artículo 130. Para una crítica de los temas tratados durante el debate de dichas reformas, véase Monsiváis (1992). 
- Dos temas se mantuvieron intactos: que no existan alusiones religiosas en los nombres de los institutos políticos, y que en los templos no se celebren reuniones de carácter político.

La novedad central, como se anotaba líneas antes, es que la reforma constitucional de 1992 agregó a la prohibición para asociarse, otra restricción: la de realizar proselitismo en favor o en contra de candidatos o partidos. ${ }^{7}$ A partir de esas características se deriva una serie de regulaciones específicas en materia electoral, como se verá más adelante.

\section{La regulación electoral}

En este apartado serán revisados con cierto detalle los contenidos mínimos en materia religiosa de las 33 regulaciones electorales en el país; es decir, las correspondientes a las 32 entidades federativas y la federal, representada por el Código Federal de Instituciones y Procedimientos Electorales (Cofipe).

En México existen varios entendidos legales que limitan la participación política de los ministros de culto en materia electoral o que restringen el uso que los partidos pueden hacer de vías religiosas. Esos entendidos fueron detallados en 15 prohibiciones legales que fueron agrupadas en dos grandes bloques: siete restricciones para los partidos y ocho limitaciones para los ministros, como se muestra en el cuadro 2.

De la comparación de los cuadros 1 y 2 es posible derivar que al menos cuatro temas de la reforma constitucional de 1992 se mantienen presentes en varias de las leyes electorales del país:

\footnotetext{
7 Para las elecciones de 2003, diversos documentos emitidos por ministros católicos causaron polémica porque su contenido, si bien se relacionaba con las elecciones, se prestaba a interpretaciones diversas, entre ellas, la de veladamente inducir al voto en contra de algunas opciones políticas. Particular polémica causó la Instrucción Pastoral circulada por el obispo de Querétaro, titulada "Un católico vota así”, del 27 de abril de 2003. Pero ese documento eclesial no fue el único que se generó, pues se han encontrado al menos otros 11 documentos católicos de pública difusión con motivo del proceso electoral de 2003 (Díaz Domínguez, 2003). Cabe destacar que las cartas pastorales en materia electoral no son nuevas en México, ya que datan de 1981 en la época reciente (Soriano, 1999).
} 


\section{Cuadro 2 \\ Quince restricciones en materia religiosa en la legislación electoral mexicana}

\begin{tabular}{|c|c|c|}
\hline Número & Restricciones para los partidos & Restricciones para los ministros \\
\hline 1 & No utilizar alusiones religiosas & No ser funcionario electoral \\
\hline 2 & $\begin{array}{l}\text { No depender de ministros o } \\
\text { iglesias }\end{array}$ & No ser auxiliar electoral \\
\hline 3 & $\begin{array}{l}\text { No incluir en la propaganda } \\
\text { motivos religiosos }\end{array}$ & No ser observador electoral \\
\hline 4 & $\begin{array}{l}\text { No recibir financiamiento de } \\
\text { ministros o iglesias }\end{array}$ & $\begin{array}{l}\text { Ser inelegible como candidato, } \\
\text { a menos que se establezca un } \\
\text { número de años para separarse } \\
\text { del ministerio con antelación }\end{array}$ \\
\hline 5 & $\begin{array}{l}\text { Violaciones en materia religiosa } \\
\text { pueden ser causal de pérdida } \\
\text { de registro }\end{array}$ & No tener presencia en la casilla \\
\hline 6 & $\begin{array}{l}\text { Violaciones en materia religiosa } \\
\text { pueden ser causal de sanción } \\
\text { administrativa }\end{array}$ & No realizar proselitismo \\
\hline 7 & $\begin{array}{l}\text { Violaciones en materia religiosa } \\
\text { pueden ser causal de nulidad } \\
\text { de la elección }\end{array}$ & $\begin{array}{l}\text { Ante presuntas conductas } \\
\text { indebidas, el órgano electoral } \\
\text { está facultado para turnar el } \\
\text { caso a Gobernación }\end{array}$ \\
\hline 8 & & $\begin{array}{l}\text { Ante presuntas conductas } \\
\text { indebidas, el órgano electoral } \\
\text { está facultado para imponer di- } \\
\text { rectamente un sanción al minis- } \\
\text { tro de culto }\end{array}$ \\
\hline
\end{tabular}

Fuente: Códigos y leyes electorales mexicanos vigentes al 30 de junio de 2003, www.trife.org.mx.

- Se mantiene la prohibición constitucional para que los partidos no hagan alusiones religiosas en su emblema, propaganda o plataforma electoral. ${ }^{8}$

${ }^{8}$ Particular atención merece el Anexo de Jaime Cárdenas (Cárdenas et al., 2000) en el cual discute la inconstitucionalidad de este tipo de prohibiciones, en específico la contenida en el Cofipe sobre dos quejas genéricas radicadas en los expedientes JGE/ QPRI/CG/015/99 y JGE/QPAN/CG/016/99 contra el Partido Revolucionario Institucional. Ese partido impugnó la segunda de las quejas donde era sancionado y obtuvo la revocación del acto en la sentencia SUP-RAP-032/99, al resolver el Tribunal Electoral del Poder Judicial de la Federación que se trataba de expresiones en ejercicio de la libertad religiosa del entonces aspirante a candidato a jefe de gobierno, Roberto Campa (caso que se analiza más adelante). Sin embargo, el propio Tribunal actualmente sostiene la constitucionalidad de dicha restricción y ha sentado jurisprudencia, de observancia obligatoria, por la cual interpreta que los partidos políticos no son titulares de libertad religiosa (Tesis S3ELJ 22/2004). 
- Para ser votado, se requiere no ser ministro de culto, ${ }^{9}$ o bien observar la calidad establecida en la ley que señala un cierto tiempo de separación del ministerio antes de aspirar a una candidatura.

- Permanece el carácter no político de reuniones en los templos.

- Prácticamente todas las normas electorales prohíben la intervención política con proselitismo por parte de los ministros.

Es importante resaltar que sólo una de las cuatro características señaladas limita a los partidos políticos, mientras que las tres restantes se dirigen a los ministros.

De la revisión puntual de cada código o ley electoral de acuerdo con las 15 variables citadas, se obtuvo el cuadro 3, donde se aprecia que en todos los códigos electorales se hallan presentes cuatro prohibiciones:

- Que los partidos no se sirvan de alusiones religiosas.

- Que no exista dependencia o subordinación del partido a los ministros de culto.

- Que los partidos no reciban financiamiento (en efectivo o en especie) de ministros o asociaciones religiosas.

- Que en la propaganda los partidos no utilicen imágenes o alusiones religiosas.

En 32 leyes se prohíbe que los ministros de culto induzcan el voto en favor o en contra de partido o candidato alguno o que fomenten la abstención, exceptuando Guanajuato. En 31 casos, las autoridades electorales pueden turnar el expediente a la Secretaría de Gobernación (Segob), que cuenta con facultades legales expresas en materia de sanciones a ministros de culto (exceptuando Guanajuato e Hidalgo). ${ }^{10}$

Pero debe aclararse que ante la presunta participación indebida de un ministro de culto, en seis de los 33 códigos electorales

${ }^{9}$ Para este requisito legal, diversos candidatos obtuvieron una constancia que acreditaba su no registro como ministro de culto en cualquier asociación religiosa inscrita por la Secretaría de Gobernación.

${ }^{10}$ Las elecciones celebradas en 2003 tuvieron como resultado 15 denuncias ante la Secretaría de Gobernación por documentos pastorales, por declaraciones en medios de comunicación o por actividades dentro del templo de parte de diversos ministros de culto, las cuales fueron, presumiblemente, en favor o en contra de candidatos y partidos políticos. Cinco casos resultaron con extrañamientos para los ministros de culto. Entre los ministros exhortados sólo hubo un obispo, el de Aguascalientes, además de sacerdotes de Guadalajara, Aguascalientes y Estado de México, así como un pastor de la Iglesia Pentecostal en Chiapas (Secretaría de Gobernación, 2003). 


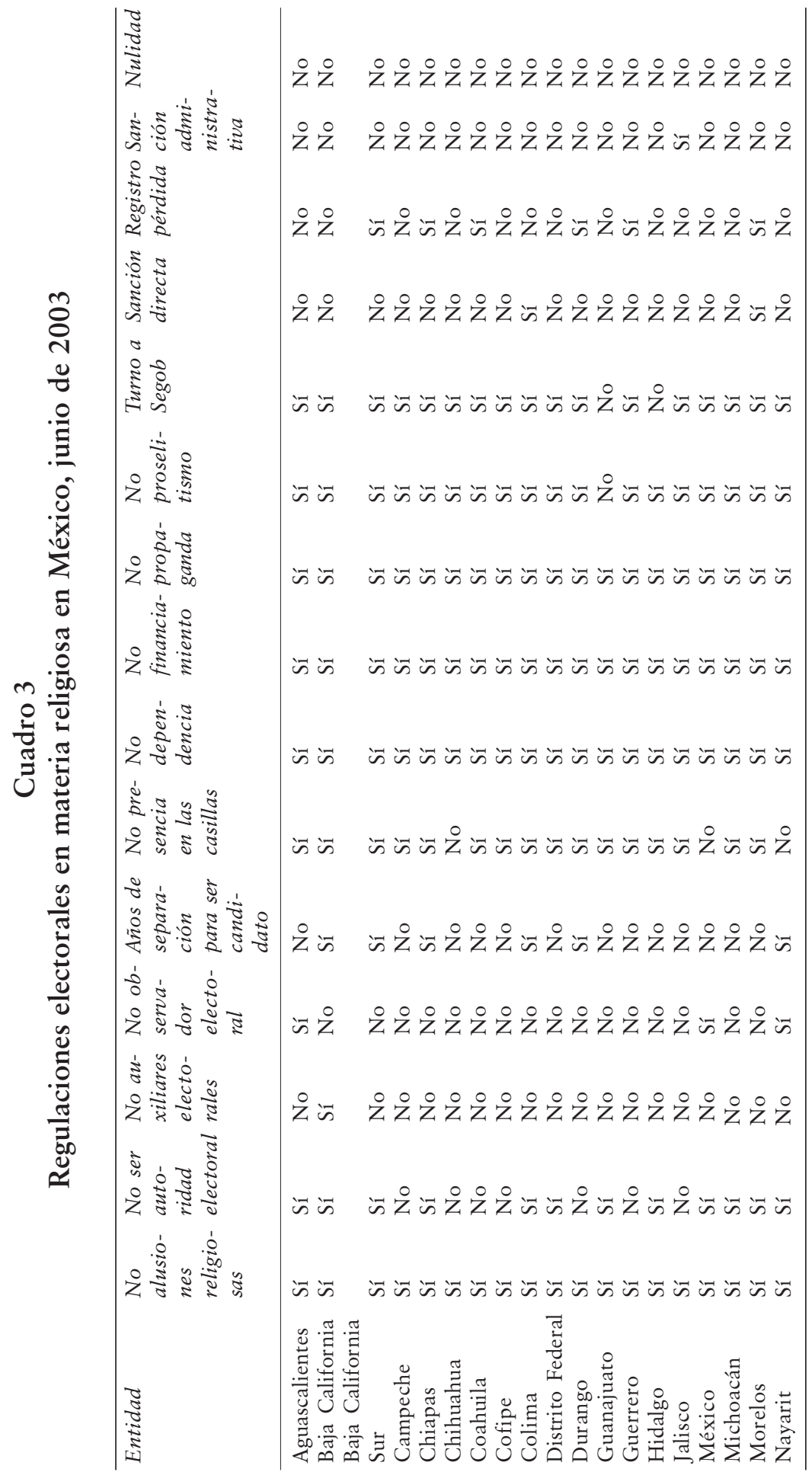




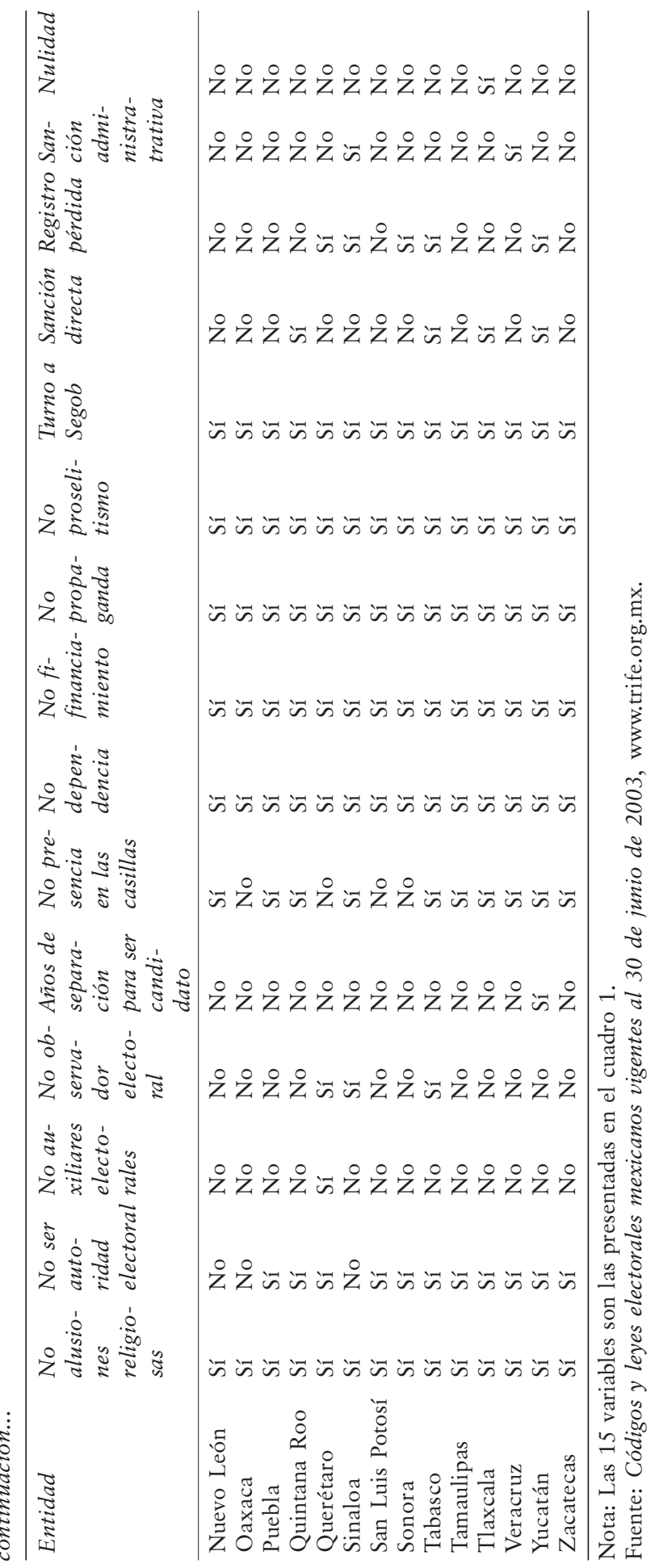


analizados, las autoridades electorales cuentan con facultades expresas para sancionarlos directamente sin necesidad de acudir a la Segob. Dichas autoridades son las de Tabasco, Morelos, Tlaxcala, Yucatán, Colima y Quintana Roo.

Por otro lado, si un partido es apoyado por un ministro de culto mediante la predicación, sólo en 14 leyes se señala expresamente que tal conducta amerita alguna sanción. Las 19 restantes son omisas al respecto.

De los 14 casos que indican sanción, en 10 se señala que ser beneficiado por la prédica política directa puede ser causal de pérdida de registro (para partidos locales, porque los nacionales están sujetos al Cofipe). Los 10 estados que castigan con pérdida de registro a un partido político local por el beneficio de la prédica política son: Tabasco, Morelos, Querétaro, Yucatán, Baja California Sur, Chiapas, Coahuila, Durango, Guerrero y Sonora.

En dos estados más, si bien ese beneficio ilícito no se castiga con pérdida de registro, sí se estipula como una causal específica de sanción administrativa, siendo los casos de Veracruz y Jalisco. Por su parte, Sinaloa presenta la particularidad de detallar grados de sanción para esa falta específica, grados que van desde diversas sanciones administrativas hasta la pérdida de registro del partido político local. El decimocuarto caso de los estados que sancionan la prédica política, Tlaxcala, muestra una variación interesante: el partido beneficiado por la prédica política no es sancionado con multa ni con pérdida de registro en caso de ser partido local, pero si el candidato beneficiado gana, puede declararse nula la elección.

Las regulaciones estudiadas también incluyen prohibiciones en diversas etapas del proceso electoral, como impedir la presencia de ministros de culto en las casillas (en 26 casos), pertenecer a la autoridad electoral (en 23), ser observador electoral (en seis) o fungir como auxiliar o asistente electoral (en dos leyes). Por último, en siete códigos se detalla el número de años de separación del ministerio necesarios para que el ciudadano pueda aspirar a registrarse como candidato, y que típicamente es de cinco, excepto en Baja California, que es de seis.

Es muy importante tener en cuenta que la omisión en algunas regulaciones no implica que si las conductas ocurren, no puedan ser analizadas por los órganos responsables, pues como toda norma, está sujeta a interpretación por parte de las autoridades administrativas y jurisdiccionales. Lo que el presente análisis resalta es que dentro de la literalidad de las reglas se halle regulado 
un determinado supuesto; es decir, que ese recuento parte de un criterio estrictamente gramatical. De acuerdo con esa óptica de análisis literal, ahora será posible ubicar las legislaciones electorales en materia religiosa en dos dimensiones: restricciones para partidos y prohibiciones para ministros. ${ }^{11}$

\section{Ubicación de las legislaciones electorales}

Con las 15 variables ya divididas en dos grupos, se procedió a construir los índices respectivos mediante la asignación y suma de valores. Para el grupo de las limitantes a los partidos se dio valor 1 en los casos donde se prohíben alusiones religiosas, dependencia de ministros, financiamiento de iglesias y propaganda religiosa, que son los casos regulados por todas las normas electorales del país. Se otorgó valor 2 en los casos donde se prevé una sanción administrativa explícita, y un valor de 3 donde se sanciona con la pérdida de registro o la nulidad de la elección.

Para el conjunto de restricciones a ministros, se asignó el valor 1 en aquellos casos donde se impide ser autoridad electoral, estar en la casilla o realizar proselitismo, y donde el órgano electoral correspondiente esté facultado para turnar el expediente del ministro presuntamente infractor a la Segob. ${ }^{12}$ El valor 2 se otorgó a los estados donde se prohíbe a pastores y sacerdotes ser auxiliares y observadores electorales y donde se explicite el número de años de separación del ministerio necesarios para aspirar a una candidatura. Se asignó el valor 3 donde la ley faculta a la autoridad electoral para sancionar directamente a los ministros de culto.

En todos los casos donde no existe la variable o característica, se anotó un cero y se procedió a sumar los valores para obtener los dos índices. ${ }^{13}$ Los datos del índice de restricciones para los ministros de culto arrojaron que dicho índice toma valores del 2 al 9, donde 2 significa escasas prohibiciones para pastores y sacerdotes, mientras que el 9 se traduce en numerosas limitantes para los ministros.

${ }^{11}$ Con esta ubicación se espera explicar de manera alternativa por qué asuntos relacionados con alusiones religiosas en otras elecciones, como las municipales del Estado de México, las de gobernador en Sonora y las de diputado federal en Michoacán, por ejemplo, fueron resueltos de manera diferente por los jueces electorales.

${ }^{12}$ Dicha facultad fue ejercida en 2003 por los órganos electorales de Querétaro, Jalisco y Estado de México, pues esas tres denuncias fueron parte de los 15 casos que resolvió la Segob por el proceso electoral de 2003.

${ }^{13}$ La suma fue realizada sin ponderaciones; es decir, fue una suma aritmética. 
Los estados con el mayor valor para este índice fueron Tabasco, Yucatán y Colima, lo cual no parece sorprender por las historias garridistas y aquellas que se atribuyen a Felipe Carrillo Puerto (Martínez Assad, 1991). El valor 8 sólo se presenta en un estado: Baja California. El valor 7 lo presentan cinco estados: Morelos, Nayarit, Quintana Roo, Querétaro y Tlaxcala. Para el valor 6 hallamos a tres entidades: Aguascalientes, Baja California Sur y Chiapas. El valor 5 fue para los estados de Durango, México y Sinaloa. El valor 4 se observa en el Distrito Federal, Michoacán, Puebla, Tamaulipas, Veracruz y Zacatecas. El valor 3 lo observamos en Campeche, Coahuila, Guerrero, Hidalgo, Jalisco, Nuevo León, San Luis Potosí, Sonora y para el Cofipe. Finalmente, el valor 2 se ubica en Guanajuato, Oaxaca y Chihuahua. Debemos resaltar que conforme el valor del índice desciende, vamos encontrando entidades con una mayor tradición religiosa, y particularmente aquellas que tuvieron presencia cristera.

Los datos del índice de limitantes para los partidos políticos muestran que dicho índice toma valores que van del 4 al 9, donde 4 implica una regulación laxa y 9 significa que existen abundantes restricciones para los partidos en materia religiosa.

El estado con el mayor valor dentro del índice de restricciones religiosas a los partidos políticos es Sinaloa. El valor 7 es compartido por 11 estados: Tabasco, Yucatán, Morelos, Querétaro, Tlaxcala, Baja California Sur, Chiapas, Durango Coahuila, Guerrero y Sonora. El valor 6 lo presentan sólo Veracruz y Jalisco. El valor menor de la escala, 4, lo vemos en las 19 entidades federativas restantes. Fuera de los estados con cierta tradición anticlerical (o "comecuras", como coloquialmente también se suele decir), parece existir una regulación uniforme en dos grupos, los del valor 7 y los del valor 4, que es el menor del índice para partidos políticos. Cabe mencionar que el Cofipe es uno de los 19 códigos que menos prohibiciones religiosas contiene.

Una vez obtenidos ambos índices, se procedió a graficarlos de modo que se tuviera la ubicación de cada ley electoral, como se muestra en la figura I, donde se presenta un plano cartesiano cuyos ejes contienen, de menos a más, restricciones para ministros (en el horizontal), y de menos a más, limitantes para los partidos políticos (en el vertical). Los valores de los índices que eran positivos (debe recordarse que la asignación de valores era $0,1,2$, y 3 , según las codificaciones ya citadas) se convirtieron a la escala que va de -4 a 4 con objeto de obtener, dentro del plano cartesiano, los cuadrantes que permitieran ubicar a las leyes electorales. 
Figura I

Ubicación de códigos electorales en México según restricciones para partidos políticos y para ministros de culto en 2003

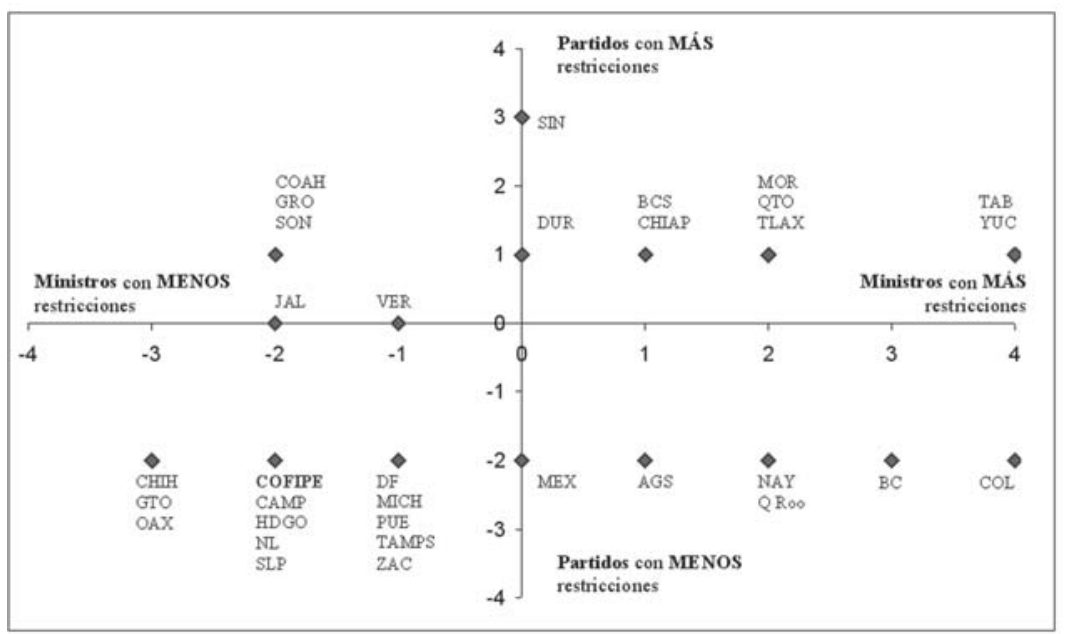

Fuente: Códigos y leyes electorales mexicanos vigentes al 30 de junio de 2003, www.trife.org.mx.

Dentro de la figura I existen cuatro cuadrantes: $a$ ) arriba a la derecha, el que incluye las más estrictas regulaciones para partidos y para ministros; $b$ ) abajo a la izquierda, el que apenas regula restricciones, tanto para partidos como para pastores y sacerdotes; $c$ ) arriba a la izquierda, donde se ubican mayores regulaciones para partidos y menos prohibiciones para los ministros, y $d$ ) abajo a la derecha, donde se encuentran las leyes que limitan más a los ministros y que limitan menos a los partidos.

A continuación procederemos a señalar dos aspectos generales de la figura i y a analizar los cuatro cuadrantes. En términos generales, de la figura I resaltan dos datos: 11 leyes se ubican en el punto 1 del eje vertical; es decir, es un grupo que en términos relativos impone mayores restricciones a los partidos. Se distingue porque abarca toda la dimensión de restricciones para los ministros; es decir, va de menores a mayores limitantes. Nos referimos a la "línea imaginaria" que puede trazarse entre los puntos donde se ubican Coahuila, Guerrero y Sonora con Durango, con Baja California Sur y Chiapas, además del grupo que incluye a Morelos, Querétaro y Tlaxcala, para finalizar con Tabasco y Yucatán. De hecho, este grupo es el mismo que presentó el valor 7 dentro del índice de restricciones para partidos. 
El segundo dato que llama la atención es que en el punto -2 del eje vertical; es decir, con bajas restricciones para los partidos, se agrupan 19 códigos, los cuales también cubren todo el espectro de limitantes para ministros. Esta segunda "línea imaginaria" puede trazarse uniendo los puntos donde se ubican Chihuahua, Guanajuato y Oaxaca, con el Cofipe, Campeche, Hidalgo, Nuevo León y San Luis Potosí, además del grupo que integran el Distrito Federal, Michoacán, Puebla, Tamaulipas y Zacatecas, sumando al Estado de México, Aguascalientes, Nayarit y Quintana Roo, siguiendo con Baja California para terminar con Colima. Este grupo está conformado por las mismas 19 leyes que presentan el valor 4, el menor de la escala que mide el grado de prohibiciones religiosas aplicables a los partidos políticos.

Lo anterior quiere decir que $58 \%$ de la leyes electorales limita a los partidos en el umbral mínimo, mientras que 34\% presenta algunas restricciones adicionales al mínimo. En ambos grupos, que representan $92 \%$ de las normas electorales del país, se ubican las dos principales modalidades de restricciones religiosas para los partidos políticos en México.

Ahora procederemos a analizar en lo particular cada uno de los cuadrantes. Respecto al cuadrante que presenta mayores regulaciones para partidos y ministros; es decir, el cuadrante de arriba a la derecha, observamos que destacan algunas regulaciones calificadas como "comecuras", las cuales se ubican en Tabasco y Yucatán, seguidas por Morelos, Querétaro y Tlaxcala, y en menor proporción por Baja California Sur y Chiapas. Algunos de estos estados vivieron experiencias de persecución religiosa en el pasado, como el "garridismo" en Tabasco (Martínez Assad, 1991), la persecución religiosa entre evangélicos y católicos en Chiapas, además de experiencias en materia educativa en Yucatán, por citar algunos ejemplos. También debe notarse que los cristeros no tuvieron fuerte presencia en dichas entidades, exceptuando Querétaro.

Respecto al bloque de 12 entidades con menores restricciones para partidos y ministros, que se ubica abajo a la izquierda, debe señalarse que ahí se ubica la legislación federal. Destacan por su escasa regulación Chihuahua, Guanajuato y Oaxaca. Después sigue el grupo encabezado por el Cofipe y enseguida el conjunto de entidades que incluyen a Michoacán y Zacatecas. En este cuadrante encontramos tres estados con presencia cristera.

Finalmente, respecto a los bloques mixtos, los estados que presentan menos restricciones para ministros y más para parti- 
dos; esto es, en el cuadrante arriba a la izquierda, hallamos a Coahuila, Guerrero y Sonora, mientras que sus opuestos, en el cuadrante que se ubica abajo a la derecha, son seis: Baja California, Colima, Nayarit, Quintana Roo, Aguascalientes y Estado de México, los cuales limitan más a los ministros y presentan menos prohibiciones a los partidos.

Una vez comentados cada uno de los cuadrantes, es menester resaltar cuatro estados que representan casos particulares: Jalisco, que cuenta con una regulación moderada para los partidos y baja para los ministros, quizá fruto de su historia cristera; los dos casos de regulación moderada: Veracruz y Durango, que se ubican muy cerca del centro del plano, y por último debe mencionarse de modo especial a Sinaloa, que norma de manera muy moderada a los ministros de culto, pero restringe fuertemente a los partidos políticos. Sinaloa es el estado que cuenta con la regulación más firme en materia religiosa aplicable a los principales destinatarios de la regulación electoral.

De la revisión y ubicación de las normas electorales mexicanas en materia religiosa se pueden establecer algunas conclusiones preliminares:

- Cincuenta y ocho por ciento de los códigos electorales contienen regulaciones mínimas para los partidos políticos en aspectos religiosos.

- Treinta y cuatro por ciento de las leyes que presentan limitaciones adicionales al umbral mínimo aplicable a los partidos no representa el punto más alto dentro de la escala de restricciones.

- Lo que realmente parece distinguir a cada uno de los dos grupos de normas electorales para los partidos no es únicamente que el segundo grupo incluya mayores sanciones explícitas, sino la amplia gama de prohibiciones aplicables a los ministros de culto que esos mismos códigos contienen.

- Algunos de los estados que tuvieron mayor presencia cristera reflejan menos limitantes para los ministros de culto.

- Finalmente, los estados donde hubo persecución religiosa sin gran resistencia popular muestran regulaciones más estrictas para los sacerdotes o pastores.

Con este marco ya resulta factible explicar de manera alternativa algunos de los criterios que han seguido los jueces electo- 
rales en asuntos presuntamente similares, donde se han presentado fallos en diferentes sentidos.

\section{La jurisprudencia electoral}

El problema que implica el respeto al principio histórico de separación entre la Iglesia y el Estado, al menos en las elecciones, no se ha resuelto con lo establecido en las leyes, pues el Tribunal Electoral del Poder Judicial de la Federación (TEPJF), máxima autoridad jurisdiccional en materia electoral en México, ha definido diversos criterios al respecto.

En los últimos cinco años, el TEPJF ha emitido siete tesis relevantes y una tesis de jurisprudencia, ésta última de observancia obligatoria para todos los órganos electorales del país. Debe precisarse que las siete tesis relevantes sólo tienen un carácter orientador, que no obligatorio. Sin embargo, resultan una fuente útil de consulta para que la autoridad administrativa norme su criterio al resolver diversos asuntos. El carácter de relevante implica que el propio TEPJF, por medio de su Sala Superior, ha decidido enfatizar una forma de resolver litigios en un tema determinado. De ahí su importancia.

En términos generales se puede afirmar que las tesis interpretan que:

- Está proscrito de la legislación el uso de propaganda electoral que consigne símbolos religiosos.

- La ley prohíbe la inclusión de símbolos religiosos en el caso de los emblemas partidistas.

- Las normas establecen el carácter inelegible de los ministros de culto como candidatos a cargos de elección popular, con independencia de que la asociación religiosa a la que pertenezcan se encuentre registrada por la Segob.

- Si la ley lo especifica, puede ser causal de nulidad de una elección el que un partido haya sido apoyado por un ministro de culto.

- Por otro lado, la tesis jurisprudencial detalla las razones por las cuales los partidos políticos mexicanos no son titulares de libertad religiosa; entre ellas destaca su carácter de entidades de interés público.

Estos son los cinco grandes entendidos del Tribunal Electoral en materia religiosa, los cuales, como puede verse, resultan ar- 
mónicos con las regulaciones contenidas en la Constitución, pero sólo en términos generales. Si el Tribunal no atendiera a las especificidades de las legislaciones electorales correspondientes, entonces aplicaría un criterio razonablemente uniforme y tal actuación no se observa en los diferentes casos. La hipótesis central es que el nivel de regulaciones en cada ámbito es la variable que explica de manera alternativa las decisiones jurisdiccionales.

Como se aprecia en el cuadro 4, las ocho tesis existentes se originaron por nueve recursos de impugnación, los cuales provinieron de cuatro recursos de apelación (Rap), es decir, resueltos en primera instancia por el Consejo General del Instituto Federal Electoral (IFE), máximo órgano electoral en materia administrativa en el ámbito federal; de un recurso de reconsideración $(\mathrm{Rec})$, esto es, resuelto en segunda instancia por una Sala Regional del TEPJF, y de cuatro recursos de revisión constitucional (JRC), es decir, provenientes de autoridades electorales de las entidades federativas, o sea, de institutos primero y de tribunales electorales locales después. Lo anterior significa que cuatro de los nueve recursos de impugnación involucrados implicaron casos regulados en entidades federativas, y los cinco restantes implicaron la aplicación de reglas federales.

De las nueve demandas que sirvieron de base para los ocho criterios en materia religiosa, en dos intervino el Partido Acción Nacional (PAN), en dos el Partido Revolucionario Institucional (PRI), en uno el Partido de la Revolución Democrática (PRD), y en uno más una coalición formada por el PAN, el PRD, el Partido del Trabajo y el Partido Verde Ecologista de México. Los tres restantes fueron presentados por dos partidos que ya perdieron su registro en 2000 y en 2003, respectivamente (Democracia Social y el Partido Alianza Social), y por una agrupación política (UNO).

Los juicios con normas locales corresponden a Tlaxcala, Estado de México, Sonora y Coahuila. Es oportuno recordar que como se desprende de la figura I, Tlaxcala es el quinto estado con mayores restricciones para ministros y forma parte del grupo de 11 estados que presentan limitaciones partidistas superiores al umbral mínimo. Los casos de Sonora y Coahuila son diferentes, pues a pesar de que forman parte del citado grupo de 11 estados con regulaciones superiores al mínimo, se distinguen por un bajo nivel de prohibiciones para ministros. Finalmente, el Estado de México forma parte de los 19 estados que limitan al mínimo a los partidos políticos y presenta limitaciones moderadas con los ministros de culto, pues se ubica cerca del centro de la figura I. 


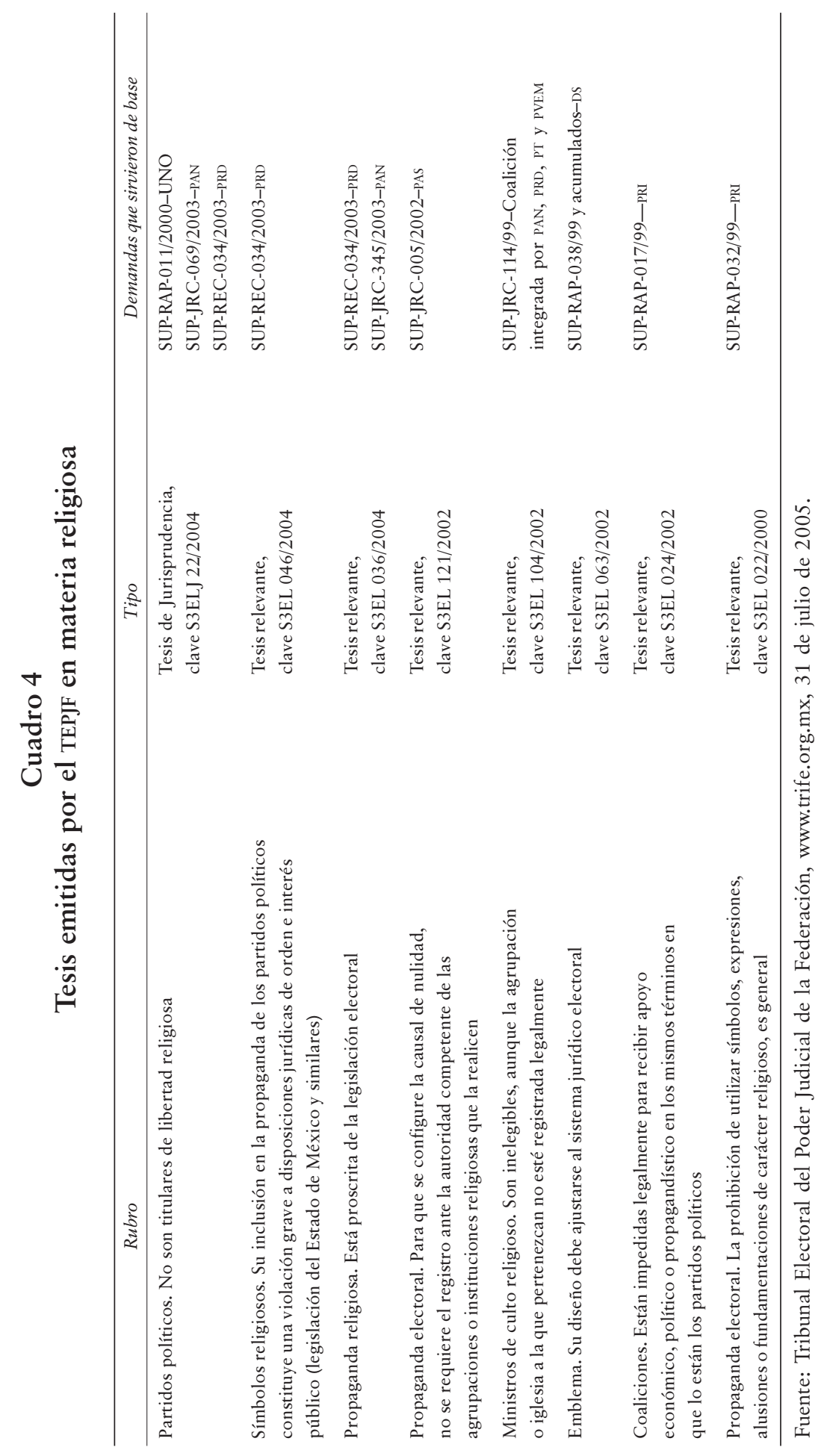


Primero se discutirán los casos locales, después los federales y finalmente un par de ejemplos que estuvieron fuera del ámbito electoral. Pero antes del análisis presentaremos las hipótesis específicas previas:

- En el caso de Tlaxcala, si a juicio del Tribunal Electoral se acreditó algún beneficio para el partido ganador por la intervención de sectores religiosos, los jueces apoyarán la anulación de los resultados. Esta hipótesis se basa en la estricta regulación del estado para los dos actores analizados, ministros y partidos.

- Para Sonora se supondrá que el Tribunal no anulará la elección ni considerará relevante la actuación de los ministros, porque la regulación estatal no incluye expresamente la anulación por motivos religiosos y porque el nivel de prohibiciones para ministros es muy bajo.

- En el caso de Coahuila se supondrá una resolución similar a la de Sonora, al estar ambos códigos ubicados en la misma posición, como se aprecia en la figura I.

- Para el Estado de México se supondrá que el Tribunal considerará motivos adicionales a la regulación local de la que existe para los ministros, pues ésta se sitúa en medio de los tres casos anteriores. Si existen motivos adicionales, quizá existan sanciones para el partido.

- Para los casos federales se supondrá, dada la ubicación del Cofipe, que no habrá nulidades por motivos religiosos, pues el índice de restricciones partidistas es el mínimo, y respecto a los ministros no habría mayores implicaciones, al ser un código con un bajo nivel de prohibiciones.

A continuación se describirá brevemente cada uno de los casos y la resolución dictada por el Tribunal, a efecto de contrastarla con las hipótesis específicas anteriores.

En el caso de Tlaxcala, la elección impugnada fue anulada al acreditarse el beneficio recibido por una inserción de prensa y mantas a cargo del patronato y otros grupos católicos que apoyaron a un candidato de Zacatelco. En el caso de Sonora, el candidato que ganó la gubernatura obsequió algunos calendarios conmemorativos con motivo de las bodas de oro sacerdotales del obispo de Ciudad Obregón, pero el Tribunal Electoral no consideró dichos calendarios como propaganda explícita ni que su difusión alterara el sentido de la votación, además de la deses- 
timación de otros argumentos, como la mayor proporción de apariciones en prensa, radio y televisión del candidato ganador y diversa propaganda negativa.

En el tercer caso, un candidato en Frontera, Coahuila, fue detectado como ministro de una asociación religiosa no registrada ante la Segob. El TEPJF determinó que debía ser sustituido por un nuevo aspirante que sí cumpliera con los requisitos legales. En el último caso local, las alusiones religiosas de un díptico del candidato a presidente municipal de Tepotzotlán, Estado de México, derivaron en la confirmación de la anulación de las elecciones por violaciones sustanciales, pues adicionalmente se difundieron logros y programas de gobierno dentro de un periodo no permitido y se colocó propaganda partidista en edificios públicos. ${ }^{14}$

En resumen, el partido involucrado fue castigado en diversos grados; es decir, con anulación, con sanción y con mandato de sustitución de candidato, y en otro caso no se determinó alguna responsabilidad. Ahora contrastaremos las hipótesis específicas con las resoluciones del TEPJF:

- En el caso de Tlaxcala, el TEPJF actuó en la dirección esperada, anulando la elección porque la ley así lo establece; es decir, por una causal religiosa.

- En el caso de Sonora se observó lo supuesto: el TEPJF desestimó el impacto político de los asuntos religiosos, para enfocarse en otros argumentos de impugnación.

- Para el caso de Coahuila se cumplieron parcialmente las hipótesis, pues si bien el candidato por su calidad de ministro resultaba inelegible, a pesar de que la legislación local no estipula el número de años de antelación para separarse del ministerio, debe señalarse que el TEPJF dejó a salvo los derechos del partido al resolver la procedencia de la sustitución. Es decir, colmó la laguna local con principios generales aplicables en virtud del mandato constitucional para el caso del ministro, y para el caso del partido sí actuó conforme a la regulación mínima esperada.

- En el caso del Estado de México, el TEPJF resolvió según lo esperado, pues determinó que existían violaciones

\footnotetext{
${ }^{14}$ El Artículo 157 del Código Electoral del Estado México ordena que 20 días antes de la jornada electoral, los gobiernos local y municipales, además de los legisladores, deben suspender la difusión de logros, obras y programas de gobierno, exceptuando los relativos a la protección civil en casos de desastres naturales, siniestros o enfermedades.
} 
sustantivas adicionales a las prohibiciones sobres alusiones religiosas.

Por lo que respecta a los cuatro recursos de apelación, dos fueron discusiones doctrinales y dos fueron casos prácticos. Los resultados fueron los siguientes: $a$ ) se discutió la improcedencia para incluir fotos en el emblema de una coalición y así aparecer en la boleta; $b$ ) se discutió si las prohibiciones aplicables a partidos lo eran también para las coaliciones, con motivo del análisis del instructivo para registrar coaliciones; $c$ ) se presentó una publicación de carácter confesional pagada por una agrupación política, y $d$ ) se analizó una demostración de fe de un candidato, que por considerarse hecha a título personal, no tuvo sanciones. ${ }^{15}$

Finalmente, en relación con el recurso de reconsideración, relativo a la anulación de las votaciones en el quinto distrito de Michoacán con cabecera en Zamora, se discutió si un folleto del candidato ganador contenía alusiones religiosas, pero el TEPJF no se pronunció sobre si dicho folleto resultaba determinante en el resultado, pues decidió que si existían causales de nulidad, no resultaba necesario entrar al fondo del asunto religioso. ${ }^{16}$

$\mathrm{Al}$ evaluar la hipótesis específica para el plano federal, se obtiene que se cumple en términos generales, pues no hubo anulaciones por motivos religiosos, ya que en el único caso de nulidad, los motivos fueron las infracciones adicionales en materia de equidad. En los tres casos restantes, el Tribunal enfatiza las interpretaciones doctrinales de la Constitución y las leyes aplicables, estableciendo que en materia electoral, los principios de la regulación impiden que los recursos de las agrupaciones se dediquen a motivos religiosos, que los partidos incluyan alusiones religiosas en sus emblemas, y que las coaliciones reciban apoyos monetarios o de otro tipo de iglesias o ministros de culto.

\section{Conclusiones}

Lo anterior permite concluir que al menos cuatro temas políticos del cuadro 1, contenidos en la reforma constitucional de 1992,

15 Éste es el caso citado por Cárdenas (Cárdenas et al., 2000) que se mencionó anteriormente. Se trató de una manifestación ante el Niño Pa por parte del entonces aspirante Campa, quien hizo la señal de la cruz (se santiguó o persignó) ante la imagen.

${ }^{16}$ Finalmente la nulidad fue decretada con base en las condiciones de equidad de la contienda, las cuales fueron violadas, pues las apariciones del candidato ganador guardaban perfecta relación con la ausencia de otros candidatos. Coincidentemente, las cuatro estaciones de radio de la localidad eran propiedad del ganador. 
han servido de base para que el TEPJF resuelva los asuntos que le son presentados. Esto significa que, en efecto, la homogeneidad que los jueces pretenden aplicar en temas muy similares tiene como base disposiciones constitucionales, pero atendiendo a las especificidades de las normas locales, pues de las tres elecciones anuladas, dos, Tepotzotlán y Zamora, no se hubieran anulado sólo por las alusiones religiosas, sino porque adicionalmente hubo otras violaciones sustanciales. El caso contrario fue el de Zacatelco, Tlaxcala, donde la anulación procedía directamente porque es la única ley electoral del país que así lo establece para candidatos ganadores que se han beneficiado de apoyos religiosos. Esto quiere decir que la uniformidad no es absoluta, sino que varía conforme a la legislación electoral aplicable.

En principio, aplicar preceptos constitucionales en concordancia con normas locales específicas pareciera ser la conclusión natural del sistema jurídico electoral. Nos valdremos de esta conclusión en un par de ejemplos para suponer qué se debe esperar de las interpretaciones normativas. Evaluemos un par de casos fuera del ámbito electoral: la extinta asociación religiosa Iglesia Católica Tradicional Méx-usa, Misioneros del Sagrado Corazón y San Felipe de Jesús (o Iglesia de la Santa Muerte), y un ministro bautista que fungió como diputado local en Aguascalientes, con objeto de pronosticar qué debía haber ocurrido.

En el primer caso, la citada asociación religiosa ya no cuenta con registro ante la Segob. ${ }^{17} \mathrm{Si}$ alguno de sus ministros de culto decidiera optar por una candidatura, le debería ser exigible, como criterio de elegibilidad, la separación del ministerio por el número de años que marque la ley. Debe recordarse el criterio orientador de la tesis relevante 104/2002, originada del caso Coahuila aquí analizado, y que señala que la calidad de ministro de culto

${ }^{17}$ Su registro consta en la publicación del 2 de octubre de 2002 en el Diario Oficial de la Federación, al no quedar controvertida la solicitud de registro constitutivo. Sin embargo, más tarde su objeto acreditado: "Predicar la palabra de Dios como lo enseñan las Santas Escrituras, conservar la liturgia de la Santa Misa Tridentina, como fomentar la unidad, el servicio, hermandad, capacitación para el trabajo y progreso espiritual entre los hombres, sin fines de lucro alguno" resultó diferente en la práctica, pues se veneraba a la "Santa Muerte", motivo por el cual le fue retirado el registro el 29 de abril de 2005 y con ello se actualizó la pérdida de derechos tales como "integrar patrimonio propio, celebrar actos jurídicos, internar al país ministros de culto de nacionalidad extranjera y transmitir y/o difundir actos de culto religioso a través de medios de comunicación masivos” (Secretaría de Gobernación, 2005). 
no se debe ignorar porque la asociación religiosa no se encuentre registrada. ${ }^{18}$

En el segundo caso, conforme a los archivos de la Dirección de Registro y Certificación de Asociaciones Religiosas de la Secretaría de Gobernación, un diputado del Congreso de Aguascalientes para el trienio 1998-2001 fue acreditado como presidente asociado y ministro de culto de una Iglesia. ${ }^{19}$ Sin embargo, consta en una carta de la propia Iglesia a la Segob que la asociación religiosa jamás le otorgó tal carácter, por lo que solicitó su baja como ministro de culto. Conforme a la segunda forma de acreditar que el candidato no es ministro de culto, el ciudadano de referencia no resultaba elegible porque formalmente su constancia hubiera establecido que sí estaba inscrito como ministro de culto ante Gobernación, a pesar de que se afirmaba que no había recibido en su Iglesia tal carácter. ${ }^{20}$ Sobrevino la solicitud de juicio político y la Subcomisión de examen previo determinó por mayoría el 18 de abril de 2000 desechar las dos denuncias interpuestas contra el diputado hidrocálido. ${ }^{21}$

Nuevos ejemplos pueden suponerse, pero los aquí ofrecidos guardan la característica de enfocarse a temas estrictamente electorales. ${ }^{22}$ Como se ve, con base en las regulaciones constitucional y locales (o la federal, según el caso) puede sugerirse una explicación alternativa que ayude a entender por qué en algunos casos existen sanciones en diversos grados a los partidos políticos que presuntamente son beneficiados por actos religiosos. Y dicha explicación alternativa está en las peculiaridades de los

${ }^{18}$ Debe recordarse que actualmente existen en materia electoral dos formas de acreditar que el candidato no es ministro de culto: con la protesta de decir verdad, y con la constancia de no registro según los archivos de la Segob. En este sentido, el TEPJF parece no quedar satisfecho con el segundo, sino que apela al principio de exhaustividad.

${ }^{19}$ Se trata de la Iglesia Bautista de la Fe, de Calvillo, Aguascalientes. El pastor representante de la Iglesia Bautista Bíblica de Ciudad Mante, Tamaulipas, inscribió el 22 de julio de 1993 al ciudadano Gonzalo Nieves Mota como ministro de culto.

${ }^{20}$ Sin embargo, en todo el debate sobre este caso, integrantes del PRI señalaron que el 24 de abril de 1994, en la Notaría 29 de Aguascalientes, quien a la postre fuera diputado por el PAN protocolizó su registro como ministro de culto.

${ }^{21}$ Gaceta Parlamentaria de la H. Cámara de Diputados del H. Congreso de la Unión, año III, número 521, del viernes 3 de mayo de 2000.

${ }^{22}$ Otro caso es el del Comisionado del Instituto Federal de Acceso a la Información, Horacio Aguilar, de quien se afirma que cuenta con la orden del diaconado en su carácter de permanente (carácter que dentro del catolicismo le permite acceder a este grado del ministerio ya casado, pero sin poder alcanzar el sacramento del presbiterado). $\mathrm{Si}$ este funcionario aspirara a ser candidato, le sería exigible separarse del ministerio cinco años antes. Aunque, de hecho, ya declinó una invitación a participar como candidato a diputado local por el distrito xxx del Estado de México el pasado 10 de enero de 2006 (Instituto Federal de Acceso a la Información, 2006). 
códigos electorales y su ubicación dentro del panorama nacional, lo que permite prever con cierto grado de éxito, el sentido de las resoluciones jurisdiccionales.

\section{Bibliografía}

Blancarte, Roberto (1992), Historia de la Iglesia Católica en México, 1929-1982, Fondo de Cultura Económica, México.

Cárdenas Gracia, Jaime, Alan García Campos y Santiago Nieto Castillo (2000), "Anexo. El Estado laico y el Instituto Federal Electoral”, en Estudios jurídicos en torno al Instituto Federal Electoral, unAm, México, pp. 167-205.

Díaz Domínguez, Alejandro (2003), "Un católico vota asî”, Milenio Diario, domingo 18 de mayo, México, p. 19.

Gill, Anthony (1999), “The Politics of Regulating Religion in Mexico: The 1992 Constitutional Reforms in Historical Context”, Journal of Church and State, 41 (4): 761-794.

Instituto Federal de Acceso a la Información (2006), Comunicado de prensa IFAI/001/06, Instituto Federal de Acceso a la Información, México.

Jiménez Urresti, Teodoro Ignacio (1996), Reestreno de relaciones entre el Estado mexicano y las Iglesias, Themis, México.

Margadant, Guillermo F. (1991), La Iglesia ante el Derecho mexicano. Esbozo histórico-jurídico, Miguel Ángel Porrúa, México.

Martínez Assad, Carlos (1991), El laboratorio de la Revolución. El Tabasco garridista, $3^{\text {a }}$ ed., Siglo xxi Editores, México.

Meyer, Jean (2000), La cristiada, vol. 3 Los cristeros, 15ª ed., Siglo xxi Editores, México.

(2001), La cristiada, vol. 1, $19^{a}$ ed., Siglo xxi Editores, México. 
(2002), La cristiada. vol. 2 El conflicto entre la Iglesia y el Estado (1926-1929), $17^{\mathrm{a}}$ ed., Siglo xxi, editores, México.

Monsiváis, Carlos (1992), "Tolerancia religiosa, derechos humanos y democracia", en A. A. V. V., Las Iglesias evangélicas y el Estado mexicano, CUPSA, México.

Portes Gil, Emilio (1934), La lucha entre el poder civil y el clero. Estudio histórico y jurídico del Sr. Lic. Don Emilio Portes Gil, Procurador General de la República, México (mimeo).

Secretaría de Gobernación (2003), Boletín 210, Secretaría de Gobernación, México.

(2005), Boletín 87, Secretaría de Gobernación, México.

Soberanes Fernández, José Luis (1998), “La nueva legislación sobre libertad religiosa en México (con referencia a las reformas de 1992)", en Ochenta años de vida constitucional en México, unam-Cámara de Diputados, México, pp. 107-124.

Soriano Núñez, Rodolfo (1999), En el nombre de Dios. Religión y democracia en México, Instituto Mora-Instituto Mexicano de Doctrina Social Cristiana, México.

Recibido: 23 de agosto de 2005. Reenviado: 6 de febrero de 2006. Aceptado: 9 de marzo de 2006.

Alejandro Díaz Domínguez. Licenciado en filosofía por el Instituto de Formación Sacerdotal de la Arquidiócesis de México, posteriormente licenciado en ciencia política por el Instituto Tecnológico Autónomo de México (ITAM). Ha ocupado cargos en el Instituto Federal Electoral, tales como: investigador en materia de fiscalización y coordinador de asesores. También ha sido parte del Instituto Electoral del Distrito Federal como asesor del presidente de la Comisión de Fiscalización; ha sido asesor en la Cámara de Diputados y fue investigador externo para la Universidad de Harvard en materia de financiamiento público local a partidos políticos en México. Actualmente es secretario particu- 
lar del magistrado presidente del Tribunal Electoral del Distrito Federal. Sus líneas de investigación se centran en los temas alrededor de las prerrogativas a los partidos, la religiosidad y la preferencia política; lo electoral se refiere al financiamiento público que los partidos reciben, sus recaudaciones privadas y la fiscalización de sus recursos y lo religioso va entrelazado con la intención de voto, con las implicaciones teológicas y prácticas de la agenda de la Iglesia Católica. Entre sus publicaciones destacan: el suplemento dominical "Contextos" de Milenio Diario, durante los últimos cuatro años, bajo la coordinación de Yuriria Sierra; "Algunos determinantes de la preferencia por y la satisfacción con la democracia en México", con Alejandro Poiré, en prensa, SEGOB, México, y "¿Realmente influyen los ministros de culto en la intención de voto?”, Revista Perfiles Latinoamericanos, FlACSO, México, número 28, de próxima aparición. 